\title{
Rancang Bangun Sistem Kunci Pintu Digital Berbasis Arduino Mega 2560
}

\author{
Raka Mohamad Eka Tama ${ }^{1}$, Hendi Hermawan ${ }^{2}$, Henny Pratiwi ${ }^{3}$ \\ ${ }^{1}$ Progam Studi Informatika, Universitas Pembangunan Jaya, \\ raka.mohamadeka@student.upj.ac.id \\ ${ }^{2}$ Progam Studi Informatika, Universitas Pembangunan Jaya, hendi.hermawan@upj.ac.id \\ ${ }^{3}$ Progam Studi Informatika, Universitas Pembangunan Jaya, heny.pratiwi@upj.ac.id
}

\begin{abstract}
Most doors still use manual keys that still have flaws like keys that are easy to duplicate, the small lock shapes make keys easily lost. Therefore, it takes a system that can replace the manual key function, one of which is to replace the manual key with password usage. This research provides an alternative solution by securing the door using a password that features a notification message to alert the owner of the house or room when there are people who do not have access to try to enter. The development done in this research is using keypad as input password. The method used in the development of this system is a prototype method where this method has seven stages of needs gathering, prototype building, prototype evaluation, coding system, system testing, system evaluation, and system implementation. This system uses Arduino Mega 2560 module equipped with microcontroller Atmega 2560 as main device and supporting device that used is GSM SIM800L, ultrasonic sensor and door lock solenoid. After passing several experimental tests it can be concluded that the system can run as expected.
\end{abstract}

Keywords : Prototype, Arduino Mega 2560, Microcontroller Atmega 2560, GSM SIM800L

\begin{abstract}
Abstrak : Kebanyakan pintu masih menggunakan kunci manual yang masih memiliki kekurangan seperti kunci mudah untuk diduplikasi atau digandakan, bentuk kunci yang kecil membuat kunci mudah hilang. Oleh karena itu, dibutuhkan sebuah sistem yang dapat menggantikan fungsi kunci manual, salah satunya adalah dengan menggantikan kunci manual dengan penggunaan password. Penelitian ini memberikan alternatif solusi dengan pengamanan pintu menggunakan password yang dilengkapi fitur berupa notifikasi sms untuk memberikan peringatan kepada pemilik rumah atau ruangan ketika adanya orang yang tidak memiliki akses mencoba masuk. Pengembangan yang dilakukan pada penelitian ini adalah menggunakan keypad sebagai input password. Metode yang digunakan dalam pengembangan sistem ini adalah metode prototipe dimana metode ini memiliki tujuh tahapan yaitu pengumpulan kebutuhan, membangun prototipe, evaluasi prototipe, mengkodean sistem, pengujian sistem, evaluasi sistem, dan implementasi sistem. Sistem ini menggunakan modul Arduino Mega 2560 yang dilengkapi dengan mikrokontroler Atmega 2560 sebagai perangkat utama dan perangkat pendukung yang digunakan adalah GSM SIM800L, sensor ultrasonik dan solenoid door lock. Setelah melewati beberapa kali percobaan pengujian dapat disimpulkan bahwa sistem ini dapat berjalan seperti yang diharapkan.
\end{abstract}

Kata Kunci : prototipe, arduino Mega 2560, mikrokontroler Atmega 2560, GSM SIM800L. 


\section{PENDAHULUAN}

Masalah pencurian saat ini sedang marak terjadi, menurut data kepolisian Polda Metro Jaya berdasarkan laporan statistik kriminal pencurian 2017, pada tahun 2016 terjadi 43.842 kasus pencurian. Hal ini dapat diantisipasi dengan memanfaatkan teknologi yang ada, yaitu dengan menciptakan sebuah teknologi berupa alat yang mampu mendeteksi pencurian. Alat ini tentunya akan sangat dibutuhkan dan membantu agar masalah pencurian ini dapat diantisipasi. Seseorang biasanya akan mencuri atau mengincar benda-benda berharga dan memiliki harga jual yang tinggi. Dan biasanya bendabenda penting atau benda-benda berharga akan disimpan di dalam sebuah ruanganruangan tertentu atau mungkin ruangan khusus.

Untuk masuk kedalam sebuah ruangan semua orang pasti harus melalui akses masuk ruangan, akses masuk sebuah ruangan biasanya berupa pintu, ada yang menggunakan pintu tralis, pintu kayu, pintu besi dan lain-lain. Sebuah pintu pasti akan mengandalkan sebuah kunci untuk menjaga ruangannya tetap aman dan pintu ini hanya bisa dimasuki oleh orang-orang yang memiliki kunci sebagai akses masuk ruangan. Namun kunci masih memiliki banyak kekurangan antara lain adalah, kunci mudah untuk diduplikasi atau digandakan, bentuk kunci yang kecil juga seringkali membuat kunci mudah hilang, terselip dan mungkin jatuh ditempat yang tidak aman, oleh karena itu dibutuhkan sebuah alat yang dapat menggantikan kunci manual menjadi kunci digital dan dapat memberi peringatan jika ada orang lain yang ingin masuk kedalam ruangan selain orang yang memiliki akses masuk ruangan.

\section{Tujuan Penelitian}

Dalam penelitian ini tujuannya adalah untuk Merancang bangun prototipe sistem kunci pintu digital berbasis arduino yang dapat menggantikan fungsi kunci pintu manual, dan dapat memberi peringatan melalui sms apabila terdapat orang lain yang tidak memiliki akses memasuki ruangan, serta penelitian ini juga dilakukan sebagai kontribusi penerapan pengetahuan yang didapat untuk pengembangan teknologi.

\section{KAJIAN PUSTAKA \\ Mikrokontroler}

Menurut Setiawan (2011:1) mikrokontroller adalah suatu IC dengan kepadatan yang sangat tinggi, dimana semua bagian yang diperlukan untuk suatu kontroler sudah dikemas dalam satu keping, biasanya terdiri dari CPU (Central Processing Unit), RAM (Random Access Memory), EEPROM / EPROM / PROM / ROM, I/O, Serial \& Parallel, Timer, Interupt Controller.

\section{Arduino Mega 2560}

Papan pengembangan mikrokontroller yang berbasis Arduino dengan menggunakan chip ATmega2560. board ini memiliki 54 buah digital I/O pin (15 pin PWM), 16 pin analog input, dan 4 pin UART (serial port hardware). Board ini memiliki tegangan operasi sebesar $5 \mathrm{~V}$, tegangan input (yang direkomendasikan, via jack DC) sebesar $7 \mathrm{~V}-12 \mathrm{~V}$, tegangan input (limit, via jack DC) sebesar 6V-20V, Arus DC per pin I/O sebesar $20 \mathrm{~mA}$, arus DC pin $3.3 \mathrm{~V}$ sebesar $50 \mathrm{~mA}$, memori flash sebesar $258 \mathrm{~KB}, 8 \mathrm{~KB}$ telah digunakan untuk (bootloader), SRAM sebesar 8KB, dan EEPROM sebesar 4KB.

\section{Sensor ultrasonik}

Sensor ultrasonik berfungsi mengubah besaran bunyi menjadi besaran listrik atau sebaliknya. Hasil dari pantulan gelombang suara digunakan untuk mengukur jarak suatu benda. Gelombang ultrasonik mempunyai frekuensi sekitar $20.000 \mathrm{~Hz}$ yang dimana frekuensi tersebut tidak dapat didengar oleh telinga manusia. 
Cara kerja dari sensor ultrasonik adalah dengan transmitter dan receiver. Alat ini akan mengirimkan gelombang ultrasonik ke suatu target dan setelah gelombang sampai pada permukaan target, maka target akan memantulkan kembali gelombang tersebut yang akan ditangkap oleh sensor ultrasonik, kemudian sensor akan menghitung antara waktu pengiriman dan waktu diterima dari gelombang yang dipantulkan.

\section{Keypad Matrix 4×4}

Keypad Matrix $4 \times 4$ merupakan tombol-tombol yang terdiri dari 4 baris dan 4 kolom yang berfungsi sebagai input data. Keypad matrix juga merupakan suatu perangkat yang berfungsi sebagai interface antara mesin dan manusia. Sisi baris dari matrix keypad disebut juga dengan nama row 1 , row 2 , row3, dan row 4 kemudian sisi kolom disebut dengan col1, col2, col3, dan col4.

\section{Modul GSM SIM800L}

Modul GSM SIM800L adalah bagian yang berfungsi untuk berkomunikasi antara sistem dengan handphone. AT Command adalah perintah untuk mengirim dan menerima data berbasis GSM/GPRS, atau mengirim dan menerima sms. SIM800L dikendalikan melalui perintah AT.

\section{PENELITIAN TERDAHULU}

Penelitian terdahulu merupakan salah satu referensi dalam perancangan yang akan diimplementasikan dalam pengembangan sistem. Beberapa penelitian terdahulu yang digunakan sebagai referensi adalah sebagai berikut:

Penelitian yang dilakukan oleh Anip Febtriko dan Tatang Sofian yang berjudul "Perancangan Sistem Pengamanan Ruangan Berbasis Mikrokontroler (Arduino) Dengan Metode Motion Detection". Penelitian ini dibuat pada tahun 2016. Pada penelitian ini membahas tentang suatu sistem keamanan ruangan yang dilengkapi sensor PIR yang dipasang pada pintu masuk suatu ruangan maupun pada titik yang dianggap penting untuk diberi sistem keamanan. Dalam penelitian ini akan dipasang sensor passive infrared pada pintu ruangan, mikrokontroller Arduino sebagai pemerosesnya. Kemudian untuk menginformasikan menggunakan led sebagai indikator, buzzer sebagai sirine peringatan dan lcd sebagai penampil teks notifikasi keadaan. Cara kerja sensor PIR ini yaitu mampu mendeteksi adanya keberadaan orang atau tidak pada ruangan yang diberi sistem keamaan ini, selanjutnya oleh mikrokontroller Arduino akan memproses datanya untuk memerintahkan agar alarm berbunyi serta memberikan notifikasi pada lcd bahwa adanya pergerakan pada ruangan . Passive infrared Receiver yang digunakan adalah sensor PIR KC778 R kemudian range sensor PIR yang digunakan pada sistem mempunyai range maksimal 60 .

"Alarm Rumah Bebas Maling Berbasis Sensor Pir, Telepon Otomatis dan Sirine" oleh Mega Ardisa Hapsari, Nuning Suci Rianti, Ajay Rachmad Supriyanto, Candra Heri Saputro adalah mahasiswa Universitas Negeri Semarang. Sebagai usulan program kegiatan mahasiswa yang dibuat pada tahun 2015. Alarm Rumah Anti Maling ini adalah pengembangan dari CCTV sebagai salah satu perangkat pengamanan rumah. Jika CCTV hanya mampu mengambil gambar saat terjadi pencurian dan besar kemungkinan pencuri akan tetap mencuri barang yang ada di dalam rumah, Alarm Rumah Anti Maling ini nantinya akan berbunyi keras dan membuat para tetangga mendengar. Alarm Rumah Anti Maling ini bekerja dengan sistem sensor PIR dengan output berupa suara sirine dan hubungan telepon langsung kepada satpam ataupun nomor yang dituju. Alarm Rumah Anti Maling ini diharapkan memberikan manfaat dalam sistem penjagaan rumah. Perancangan dari Alarm Rumah Anti Maling ini dengan membuat rangkaian sensor PIR, dengan output berupa suara sirine dan 
dihubungkan langsung dengan telepon genggam agar saat rangkaian sensor mendeteksi adanya maling, telepon langsung menghubungi satpam atau nomor yang telah dituju.

"Perancangan Sistem Deteksi Gerak Dengan Sinar Laser Menggunakan Mikrokontroler Atmega 8 Pada Laboratorium Komputer Sekolah Tinggi Keguruan Dan Ilmu Pendidikan Pgri Pacitan" Oleh Denis Tri Priyono, Sukadi. Mahasiswa Universitas Surakarta. Sistem Deteksi Gerak Dengan Sinar Laser Mikrokontroler ATMEGA 8 Pada Laboratorium STKIP PGRI Pacitan dibuat untuk memberikan solusi keamanan di laboratorium computer STKIP PGRI. Selain itu dengan adanya aplikasi ini juga diharapka dapat mempermudah dan meringankan tugas petugas keamanan dalam menjaga keamanan kampus. Dalam pembuatan aplikasi ini menggunakan Bahasa C, Bahasa yang digunakan untuk memprogram IC mikrokontroler ATMEGA 8, CodeVisionAVR C Compiler merupakan sofware aplikasi pendukung dalam hal untuk merancang dan membuat program berbahasa $\mathrm{C}$ ke dalam Mikrokontroller ATMEGA, USB ASP-WINDRIVER merupakan driver dari Dowloader. Downloader merupakan perangkat keras yang digunakan sebagai port inputan dan output uji coba sistem dan Komponen Pendukung Sistem Deteksi Gerakan.

Penelitian yang dilakukan oleh Ruri Hartika Zain pada tahun 2013 yang berjudul "Sistem Keamanan Ruangan menggunakan Sensor Passive Infra Red (PIR) Dilengkapi Kontrol Penerangan Pada Ruangan Berbasis Mikrokontroler ATmega8535 dan Real Time Clock DS1307". Penelitian ini menggunakan sensor Passive Infra Red (PIR) KC7783R dan mikrokontroler ATmega8535 yang sudah di dukung dengan bahasa pemograman C. Sistem keamanan gedung dan rumah mewah diantaranya menggunakan kamera CCTV yang dipantau oleh operator yang diminta oleh pemilik gedung atau rumah mewah tersebut. Kamera CCTV ada yang menggunakan sensor IR dan ultrasonik, tetapi dalam penggunaannya juga dibutuhkan sumber sensor lain. Contohnya, sensor otomatis yaitu PIR sensor dengan jangkauan yang cukup panjang.

Penelitian yang dilakukan oleh Abhishek S. Parab. Mithibai College Mumbai , Maharashtra, India tahun 2015 yang berjudul "Implementation of Home Security System using GSM module and Microcontroller". Sistem ini diciptakan untuk menjaga keamanan rumah dari dalam. Dalam penelitian ini, disajikan dengan desain danimplementasi keamanan rumah nirkabel berbasis GSM sistem. Sistem ini bisa merespon dan mendeteksi secara cepat penyusup. Dalam sistem ini akan dipasang sebuah kabel dan magnet yang akan meghasilkan sinyal melalui jaringan telekomunikasi publik dan mengirim pesan atau mengalihkan panggilan untuk memberitahu si pemilik rumah bila ada penyusup yang masuk ke dalam rumah. Pesan ini berasal dari mikrokontroler yang mampu menyampaikan pesan jarak jauh melalui sms atau telpon menggunakan GSM.

\section{METODOLOGI PENELITIAN}

Metode yang digunakan pada penelitian ini adalah metode prototype. Dengan metode prototype ini pengembang dan pelanggan dapat saling berinteraksi selama proses pembuatan sistem. Tahapantahapan dalam metode prototype adalah sebagai berikut :

1. Pengumpulan Kebutuhan

Pengembang dan pelanggan dapat bersama-sama mengidentifikasikan semua kebutuhan dari sistem yang akan dibuat.

2. Membangun Prototyping

Pada tahapan ini pengembang membuat perancangan sementara yang berfokus pada penyajian keinginan pelanggan.

3. Evaluasi Prototyping 
Setelah membangun prototyping maka akan dilakukan evaluasi apakah prototipe yang sudah dibuat sudah sesuai dengan keinginan pelanggan. Jika sudah sesuai maka bisa lanjut ke langkah selanjutnya, jika belum maka harus mulai dari langkah pertama.

4. Mengkodekan Sistem

Pada tahap ini prototipe yang sudah dibuat akan diterjemahkan kedalam bahasa pemrograman.

5. Menguji Sistem

Setelah melakukan pengkodean maka harus dites terlebih dahulu menggunakan white box dan black box.

6. Evaluasi Sistem

Pada tahap ini pelanggan akan melakukan evaluasi sistem yang sudah jadi apakah sesuai dengan keinginannya atau belum. Jika sudah maka lanjut ke langkah berikutnya, jika belum maka harus ulang dari langkah 4.

7. Menggunakan Sistem

Sistem yang sudah diuji dan diterima pelanggan siap untuk digunakan.

\begin{tabular}{|c|c|c|c|}
\hline \multicolumn{4}{|c|}{$\begin{array}{l}\text { ANALISIS DAN PERANCANGAN } \\
\text { Analisis Sistem Berjalan }\end{array}$} \\
\hline & \multicolumn{3}{|c|}{ Taluin } \\
\hline & 204 & 2015 & 2016 \\
\hline \multicolumn{4}{|l|}{ Kejahatan terhadap Hak Milik /Earang } \\
\hline Petcorian & 24538 & 26298 & 26.636 \\
\hline 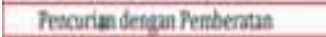 & 42.699 & 41.100 & 46277 \\
\hline Feourian Kendirnat Bernictese & 12.165 & 38309 & 37891 \\
\hline Pesensoiba/Pengtuncuran larang & 7207 & 6.960 & 7.926 \\
\hline Perhalara denea Senjiz & 788 & 721 & 650 \\
\hline Petatihan & 754 & 537 & 666 \\
\hline
\end{tabular}

Gambar 1. Kasus Kejahatan

Dari jenis kasus kejahatan di atas, pembobolan rumah kosong dikategorikan sebagai kasus pencurian dengan pemberatan, atau dalam bahasa awam biasa disebut perampokan. Dari data di atas dijelaskan bahwa pada tahun 2014 ada 24.538 kasus pencurian, naik menjadi 26.298 pada tahun 2015, dan pada tahun 2016 naik menjadi 26.636. Kasus pencurian dengan pemberatan merupakan kasus pencurian yang paling banyak terjadi yaitu 42.699 kasus pada tahun 2014, 41.100 kasus pada tahun 2015 dan 46.277 kasus pada tahun 2016.

Seperti yang dikutip di halaman pressreader bahwa sudah banyak warga yang mengantisipasi guna mencegah pembobolan rumah. Sepertiga warga mengaku, mereka biasanya mininggalkan rumah setelah mengunci pintu, jendela dan pagar serta menyalakan lampu rumah agar tidak terkesan kosong.

Dengan danya hal tersebut tentu membuat banyak orang harus lebih waspada ketika ingin meninggalkan ruangan yang menyimpan berbagai macam barang berharga. Terlebih masih banyak ruangan yang menggunakan kunci-kunci manual, dimana pada kunci manual ini kunci bisa saja hilang atau diduplikasi sehingga banyak orang yang dapat memilikinya secara mudah. Hal ini akan lebih bahaya ketika kunci yang hilang ditemukan oleh orang yang memiliki niat jahat yang pada akhirnya membuat orang jahat tersebut leluasa masuk kedalam ruangan dan mengambil barang-barang berharga yang ada. Hal-hal seperti inilah yang membuat penggunaan kunci secara manual belum efektif digunakan.

\section{PERANCANGAN SISTEM Desain Alat dan Interface}

Pada tahap ini dilakukan rancangan dari desain alat yang akan dibuat. Berikut adalah gambaran rancangan desain alat. Gambar dibawah ini adalah rancangan desain yang akan diletakan di dekat pintu yang akan dipasang sistem ini. Pada bagian luar rancangan terdapat keypad matrix 4×4 sebagai inputan yang akan ditampikan pada lcd 16x2. Pada sisi kanan adalah sensor ultrasonik HC-SR04 yang akan mendeteksi orang yang mencoba membuka pintu dengan menggunakan jarak.

Password untuk login user adalah password default, password default dapat dirubah dengan menggunakan perintah tombol D pada keypad. Dan untuk semua 
user harus menggunakan password yang sama yaitu password default.

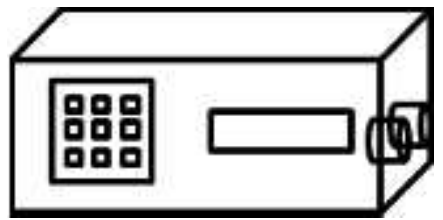

Gambar 2. Desain Alat

\section{Flowchart}

Berikut ini adalah rancangan cara kerja dari sistem kunci pintu digital ini pada penelitian ini yang direpresentasikan dalam bentuk flowchart.

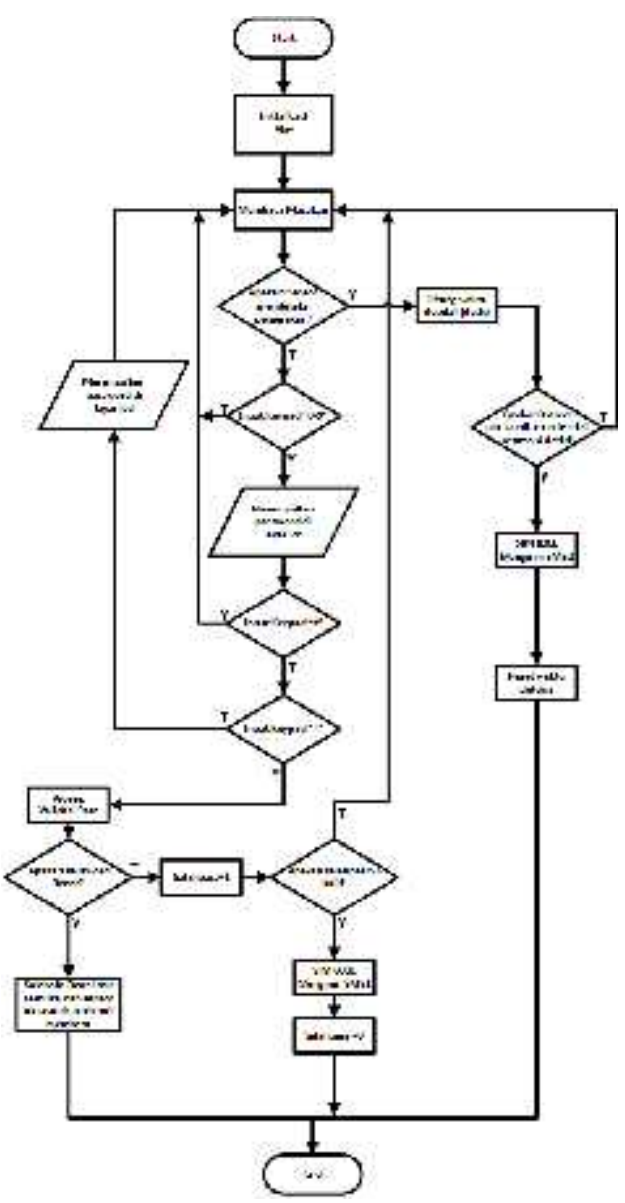

Gambar 3. Flowchart Keseluruhan Skema Rangkaian Alat

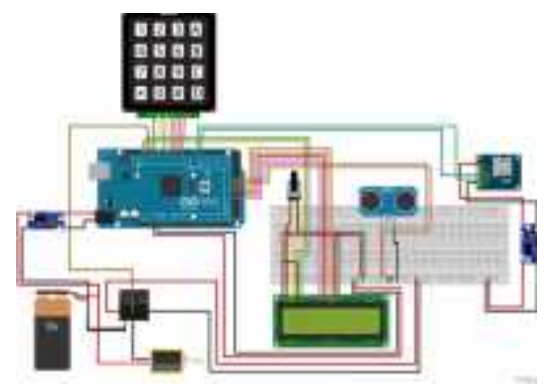

Gam

bar 4.

Skem a Rangkaian Alat

Berdasarkan skema rangkaian diatas pin yang digunakan adalah sebagai berikut:

Pin digital $2-9$ pada arduino adalah pin yang digunakan untuk keypad $4 \times 4$, pin digital 10 digunakan untuk relay, pin digital 11 digunakan untuk $\mathrm{E}$ pada bagian LCD, pin digital 12 digunakan untuk RS pada bagian LCD, pin digital 19 digunakan untuk Trigger pada bagian sensor ultrasonik, pin digital 20 digunakan untuk Echo pada bagian sensor ultrasonik, pin digital 44 digunakan untuk D4 pada bagian LCD, pin digital 42 digunakan untuk D5 pada bagian LCD, pin digital 40 digunakan untuk D6 pada bagian LCD, pin 38 digunakan untuk D7 pada bagian LCD.

\section{HASIL PENELITIAN DAN ANALISIS Gambaran Umum Objek Penelitian}

Objek penelitian pada penelitian ini adalah sistem kunci pintu digital yang menggunakan komponen seperti Arduino Mega 2560, sensor ultrasonik untuk mendeteksi pergerakan orang, keypad 4x4 untuk memasukan password, lcd 16x2 untuk menampilkan inputan keypad, solenoid door lock dan GSM SIM800L untuk mengirim sms ke orang yang memiliki akses khusus masuk kedalam ruangan. Sistem kunci pintu digital pada sebuah ruangan ini diharapkan bisa membantu untuk mengetahui siapa saja yang akan masuk ke dalam ruangan. Sering kali ruangan berada pada situasi yang sepi apalagi ketika tidak ada aktifitas yang terjadi didalam ruangan ataupun pada situasi malam hari pada saat semua kegiatan telah selesai. Oleh karena itu, sistem keamanan ini dirancang agar bisa terdeteksi jika ada seseorang yang mecoba masuk kedalam ruangan selain orangorang yang memiliki akses untuk masuk keruangan tersebut dengan menggunakan password.

\section{Gambaran Umum Subjek Penelitian}


Saat ini kebanyakan ruangan masih tidak memiliki sistem kunci pintu digital pada sebuah ruagan yang bisa memberitahu kepada orang-orang yang memiliki akses masuk ruangan bahwa ada orang lain yang tidak memiliki akses ruangan masuk kedalam ruangan. Pencuri biasanya beraksi pada saat situasi ruangan sedang sepi ataupun pada malam hari pada saat aktifitas telah berhenti. Oleh karena itu, untuk memberikan sebuah solusi yang dapat membantu mencegah terjadinya pencurian yaitu dengan membuat sistem keamanan yang menggunakan password. Sistem ini dirancang menggunakan Arduino Mega 2560 dan komponen lain seperti sensor ultrasonik, keypad $4 \times 4$, lcd, SIM800L.

\section{Tahapan Perakitan Alat}

Pada tahap ini merupakan gambar dari tiap tahapan yang dilakukan dalam perancangan sistem kunci pintu digital hingga tahap akhir.

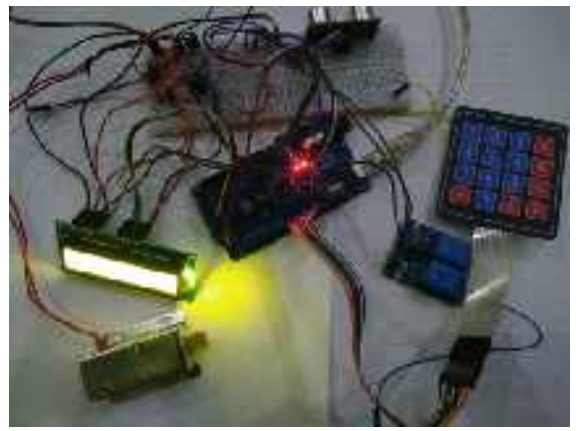

Gambar 5. Perakitan Sensor Ultrasonik

Pada gambar 5 menunjukkan tahap perakitan sensor ultrasonik untuk mendeteksi keberadaan orang

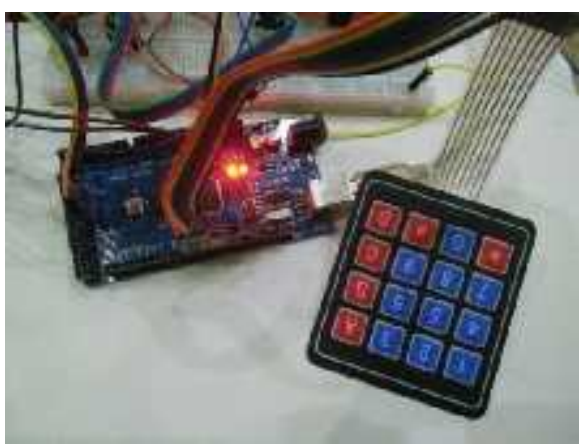

Gambar 6. Perakitan Keypad 4x4
Gambar 6 merupakan tahap perakitan keypad $4 \times 4$ untuk memasukan password.

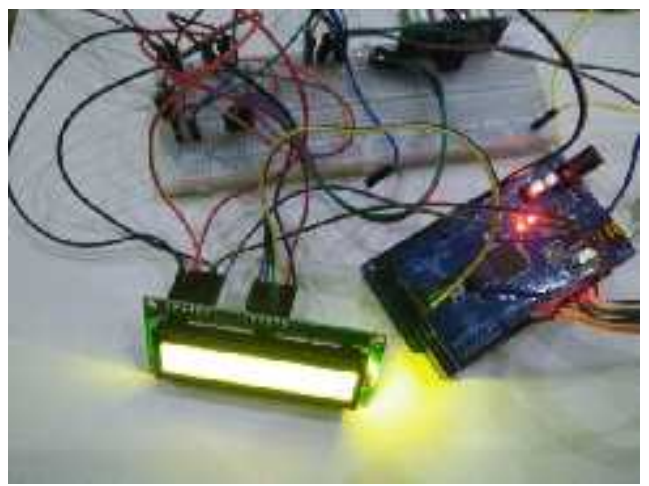

Gambar 7 merupakan tahap perakitan lcd $16 \times 2$ untuk menampilkan password yang sudah dimasukan melalui keypad $4 \times 4$.

Pada gambar 8 merupakan tahap perakitan dari seluruh komponen yang digunakan. Pada tahap ini dilakukan penggabunggan semua komponen yang sudah dirakit sebelumnya yang nantinya akan dicetak ke PCB.

\section{Gambar 7. Perakitan LCD $16 \times 2$}

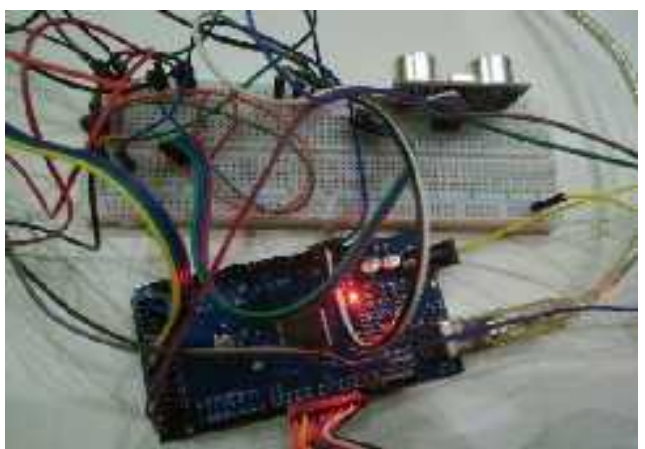

Gambar 8. Perakitan Sistem Kunci Pintu Digital

\section{Pengujian Alat/Sistem}

Pada tahap ini dilakukan pengujian alat dan sistem. Tabel 1 merupakan hasil pengujian yang dilakukan.

Tabel 1. Pengujian Black Box

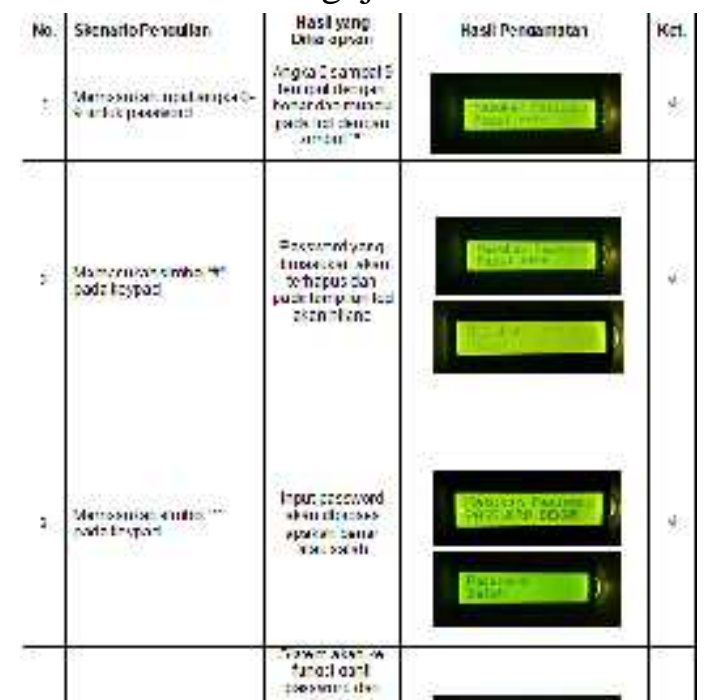


Berdasarkan tabel pengujian diatas nomor 1 merupakan hasil pengujian input angka keypad 0-9 untuk memasukan password dan akan muncul di lcd.

Nomor 2 merupakan hasil pengujian input symbol "\#” pada keypad. Jika symbol "\#” ditekan maka password akan terhapus.

Nomor 3 merupakan hasil pengujian input simbol "*” pada keypad. Jika simbol "*” ditekan maka password yang dimasukan akan diproses.

Nomor 4 merupakan hasil pengujian input huruf "D" pada keypad. Jika huruf "D" ditekan maka akan pindah ke fungsi ganti password.

\section{Pembahasan Hasil Alat/Sistem}

Sistem kunci pintu digital ini menggunakan sensor ultrasonik yang dipasang disamping pintu yang mengarah kearah pintu agar sensor dapat mengetahui jika ada orang yang mencoba masuk dengan mendeteksi menggunakan jarak. Sensor ultrasonik dapat dimatikan dengan memasukan password yang disediakan untuk orang yang memiliki akses masuk keruangan dengan menggunakan keypad $4 \times 4$ sebagai input untuk mematikan sensor dan akan diberi jeda waktu 10 detik setelah itu sensor akan kembali membaca. Jika sensor ultrasonik tidak dimatikan dan mendeteksi ada orang maka SIM800L akan mengirim notifikasi berupa sms ke orang yang memiiki akses masuk ruangan bahwa ada orang yang mencoba masuk.

Selain itu, sistem ini juga dilengkapi solenoid door lock sebagai pengunci pada pintu. Solenoid door lock ini akan terbuka jika password yang dimasukkan benar dan akan terkunci kembali dengan jeda waktu 10 detik. Jika password yang dimasukkan salah sebanyak 3 kali maka SIM800L juga akan memberi notifikasi ke ke orang yang memiiki akses masuk ruangan bahwa ada seseorang yang mencoba memasukkan password dan solenoid door lock tetap akan terkunci.

Password yang disediakan untuk orang yang memiiki akses masuk ruangan akan disesuaikan dengan jumlah orang yang sudah ditentukan siapa saja yang memiliki akses masuk keruangan. Masingmasing orang yang memiiki akses masuk ruangan anggota password yang berbeda beda. Dan untuk orang lain yang tidak memiliki akses masuk namun memiliki kepentingan akan diberikan 1 password yang berbeda dengan orang yang memiiki akses masuk ruangan.

\section{KESIMPULAN}

Berdasarkan rumusan masalah yang sudah diuraikan sebelumnya, ada beberapa hal yang membuat penulis dapat menarik sebuah kesimpulan.

1. Sistem kunci pintu digital menggunakan solenoid door lock untuk mengunci pintu, dan untuk membukanya perlu memasukkan password melalui keypad yang tersedia di sistem ini.

2. Sistem kunci pintu digital akan mengirim sms kepada pemilik melalui SIM800L, jika seseorang salah memasukkan password sebanyak tiga kali.

3. Jika terdapat seseorang didekat pintu dengan jarak minimal $70 \mathrm{~cm}$ selama 10 detik, dan seseorang tersebut tidak memasukkan password maka sistem akan mengirim sms melalui SIM800L kepada pemilik.

\section{DAFTAR PUSTAKA}

1. Febtriko, A., Perancangan Sistem Pengamanan Ruangan Berbasis Mikrokontroller (ARDUINO) Dengan Metode Motion Detection, 2016.

2. Hapsari, M.A., Alarm Rumah Bebas Maling Berbasis Sensor Pir, Telepon Otomatis dan Sirine, 2015. 
3. Mardi, Sistem Informasi Akuntansi, Ghalia Indonesia, Bogor, di akses pada tanggal 25 Mei 2018 dari

http://repository.unpas.ac.id/5502/4/BA B\%20II-AGHNI.pdf, 2011.

4. Parab, A.S., Implementation of Home Security System Using GSM Module and Microcontroller, diakses pada tanggal 19 Oktober 2017 dari http://ijcsit.com/docs/Volume\%206/vol 6issue03/ijcsit20150603212.pdf, 2015.

5. Priyambudi, H., Pengertian Metode Prototype, Tahapan dan Kelebihan Metode Prototype, diakses pada tanggal $18 \quad$ Mei 2018 dari https://androidunik.com/pengetahuan/pe ngertian-metode-prototype-dankelebihannya/, 2017.

6. Priyono, D.T., Perancangan Sistem Deteksi Gerak Dengan Sinar Laser Menggunakan Mikrokontroller Atmega 8 Pada Laboratorium Komputer Sekolah Tinggi Keguruan dan Ilmu Pendidikan PGRI Pacitan, 2012.

7. Setiawan, A., Mikrokontroler ATMEGA 8535 \& ATMEGA16 menggunakan $B A S C O M-A V R$, Andi : Yogyakarta, 2011.

8. Zain, R.H., Sistem Keamanan Ruangan Menggunakan Sensor Passive Infra Red (PIR) Dilengkapi Kontrol Penerangan Pada Ruangan Berbasis Mikrokontroller Atmega 8535 dan Real Time Clock DS1307, 2013. 